\title{
ELEMENTOS PARA \\ PENSAR LA EDUCACIÓN
}

\author{
Rubén Bravo \\ Universidad Politécnica Salesiana - Quito
}

\begin{abstract}
"En la medida que nos hagamos capaces de transformar el mundo, de poner nombre a las cosas, de percibir, de entender, de decidir, de escoger, de valorar, de eticizar el mundo, nuestro movimiento en él y en la historia envuelve, necesariamente, los sueños por cuya realización luchamos. De ahí pues que nuestra presencia en el mundo que supone elección y decisión, no sea una presencia neutra. La capacidad de observar, de comparar, de evaluar para escoger, mediante la decisión, con lo que, interviniendo en la vida de la ciudad, ejercemos nuestra ciudadanía, se erige por tanto como competencia fundamental. Si mi presencia no es neutra en la historia, debo asumir del modo más críticamente posible su carácter politico."
\end{abstract}

Paulo Freire

No podía ser más lacónico el gesto que realizamos la mayoría de ciudadanos al conocer los resultados de la evaluación en razonamiento verbal y lógico a los aspirantes a maestros, en la cual 17.877 personas que se presentaron a las pruebas alcanzaron un puntaje promedio de tan sólo 7.6/201, demostrando de esta manera, su escuálida aptitud para desempeñar la docencia. Pero más allá de la discusión pertinente sobre los resultados y procedimientos de la prueba, lo importante es que este hecho 
constituye un claro signo de la profunda crisis que vive la educación, uno de cuyos componentes es la pobrísima situación de los maestros, situación que no sólo hace referencia a los escasos ingresos que perciben, sino también a su disminuida capacidad intelectual e insuficiente preparación para el desempeño de sus funciones.

Otro elemento de esta crisis es la desarticulación de la relación entre educación y mundo, la misma que asume diferentes características: imposición de saberes producidos en los centros de desarrollo que no responden a las necesidades locales, primacía en la trasmisión de saberes, anclaje en el pasado y finalmente, autoexclusión en la medida que la escuela se vuelve sobre sí misma y se distancia de la sociedad. Estas características son forjadas por la propia dinámica del poder dominante que impulsa, bajo diferentes modalidades, una educación que hace de la escuela un espacio privilegiado de consumo cultural.

Los conocimientos, metodologías y técnicas ya elaboradas y necesarias para la productividad, las éticas y valores, los comportamientos y las conductas y sobre todo, las relaciones sociales, son impuestos a través de la educación por el orden dominante. La educación se aparta cada vez más de las lógicas de producción de conocimientos, de creación cultural y de construcción de sentidos, y se afirma en la repetición de verdades ya elaboradas por esta razón estos procesos de creación cultural, de elaboración de propuestas, de construcción de sentidos emancipatorios se gestan y se desarrollan de manera preferente fuera de los procesos educativos.

Dicha desarticulación también es producida por la heterogeneidad del movimiento, sobre todo en los procesos de cambio de época. No sólo el movimiento es desigual al interior del mundo, las lógicas que rigen esos movimientos son también diversas. El movimiento en los 
espacios de acumulación es más acelerado, su tiempo es el tiempo del progreso y la riqueza, en cambio el tiempo en la educación, que es el espacio del conocimiento y la cultura, es más lento. Por otra parte, la institucionalidad educativa en general está presa del pasado, de lo constituido, de lo ya elaborado, prisionera en la función de trasmitir la cultura a las nuevas generaciones y como tal, sus ritmos de movimiento también son lentos a pesar de la dinámica acelerada que imprime la lógica de mercado al conjunto de la sociedad, contribuyendo a ensanchar la brecha entre educación y mundo.

La mencionada desarticulación entre educación y mundo, evidencia la importancia de comprender los cambios ocurridos en la sociedad producto de la revolución tecnológica, cambios que se manifiestan en una nueva organización de la economía, cultura, poder y en general de toda la sociedad. Hoy estamos obligados a comprender este nuevo mundo, no sólo desde la perspectiva tecnológica y de mercado, sino sobre todo desde la perspectiva del conocimiento y la cultura, con el objeto de vislumbrar los nuevos regímenes de organización, administración y producción que inciden en la configuración de la subjetividad y la vida del ser humano. Como decía Freire: "como ser humano, no debo ni puedo abdicar de la posibilidad de entender el mundo, que veo que se construye, social e históricamente, en nuestra experiencia existencial, interviniendo en él, y, en consecuencia, de comunicar lo entendido. La comprensión del mundo, tanto aprendida como producida, y la comunicabilidad de lo comprendido son tareas del sujeto, en cuyo proceso precisa y debe hacerse cada vez más crítico". ${ }^{2}$

Esta comprensión del mundo nos permite visualizar de mejor manera las finalidades de nuestras acciones y relacionarnos con más claridad con el mundo 
y para hacer la educación en una zona de mayor luminosidad. Lo que hacemos no tiene valor por lo que hacemos en sí mismo, sino por las finalidades que asignamos a nuestras acciones $y$, por los impactos que generan en nosotros y los otros. Se vuelve imperativo preguntarnos ¿para qué hacemos educación, o educamos o nos educamos en ese mundo concreto, en esa realidad específica en la cual nos encontramos? Si la respuesta es para volvernos competentes en el mercado ${ }^{3}$, entonces dicha finalidad se orienta al fortalecimiento de un sistema de opresión y dominación que destruye la vida, incluido el ser humano. Pensar seriamente en lo que hacemos y buscar las formas de articular el proceso educativo al mundo para el sostenimiento de la vida y la emancipación del ser humano, es una opción totalmente válida en las actuales condiciones.

Nosotros pensamos en lo que hacemos, cuando encontramos dificultades en su curso o no estamos satisfechos con lo que hacemos, lógicamente que la visibilidad de estas dificultades y la insatisfacción con nuestros actos, son más evidentes en contextos de crisis. Actualmente muchos visualizamos el hacer educativo como un hacer deficiente, insuficiente y precario que nos causa insatisfacción. Para algunos esta insatisfacción se sitúa en la aplicación de una defectuosa pedagogía que impide la eficiente capacitación de la fuerza laboral para ponerla al servicio del mercado. Otros en cambio, no estamos satisfechos con la aplicación de una pedagogía que reproduce la dominación, la explotación y la dependencia, debido a que es un proceso que no produce conocimiento, tan sólo conduce al conocimiento y como tal queda atrapada en el pasado y en la transmisión de saberes, anulando la posibilidad de crear nuevo mundo y nueva realidad.

A pesar de que toda crisis cubre con un manto de oscuridad la realidad y no permite visibilizar más que 
las precariedades y los miedos, también desata las fuerzas de la razón, la creación y la imaginación, iluminando intensamente zonas que parecían estar eternamente cegadas por la noche. Por la información que se maneja en la sociedad respecto a la educación, creo que estamos en ese momento de crisis, al que Capra llama "punto de bifurcación"; un momento de inestabilidad en el cual pueden surgir nuevas formas de desorden, pero, originando un salto hacia adelante en la medida que se abre la posibilidad de imaginar y crear un nuevo orden ${ }^{4}$. Desde esta perspectiva, ubicarnos en un escenario de crisis con respecto a la educación, puede abrir enormes posibilidades para reflexionar sobre nuestro quehacer educativo, desde diversas miradas que nos posibiliten inscribirnos en una lógica de reflexión e innovación.

Quienes nos sentimos insatisfechos con las finalidades asignadas actualmente a la educación y sus formas instituidas para educar, creemos que es absolutamente válido y necesario preguntarnos nuevamente: ¿Qué es educar? y ¿Para qué educar?, con el objeto de visualizar mejor el horizonte y la manera cómo educamos, pues no debemos olvidar que el cómo hacemos las cosas, está en función de las comprensiones y entendimientos que tenemos de esas cosas. Actualmente hacemos una educación que anula la capacidad de asombro del ser humano y le hunde en la asimilación de ideas, creencias o conocimientos de manera acrítica; instituye unas relaciones autoritarias de competencia y dominio, por lo que, es lógico que nos preguntemos nuevamente por el sentido de la educación. Una educación de esta naturaleza anula la capacidad de creación del sujeto y lo lanza al hoyo negro de la dependencia, propicia que el polvo de la ignorancia se acumule en todos los espacios de su ser, que sus ojos se vayan apagando, se vuelvan vidriosos y las telarañas lo 
envuelvan lentamente, mientras se acomoda para descansar en la suavidad de su seda.

No estamos satisfechos con este proceso que reduce lo educativo a una práctica de inculcar una doctrina. Tampoco nos satisface la educación que pretende dar herramientas para que las apliquen ciegamente en determinadas circunstancias o en aquella que pretende desarrollar únicamente destrezas y habilidades para realizar con eficiencia ciertas acciones profesionales. Adoctrinar en determinados conceptos y capacitar en el manejo de ciertas técnicas, independiente de los contextos y los procesos históricos que vive el sujeto, de las interrogantes que se formula y la finalidades que construye, es un serio atentado contra el espíritu del ser humano. La educación tiene que orientarse al descubrimiento, a la creación, a la crítica seria, al análisis profundo y además de dar las herramientas para que el sujeto actúe en el mundo para transformarlo y transformarse junto con esa transformación del mundo, tiene necesariamente que generar los escenarios y los recursos para que los sujetos aprendan a construir sus propias herramientas.

Responder a las preguntas del ¿Qué? y del ¿Para qué? en la educación es una tarea compleja. En primer lugar, existe una estrecha relación en éstas, que se vuelven imposibles de responder la una sin la otra. Pretender comprender la educación pasa necesariamente por entender el mundo, el conocimiento, el ser humano, las relaciones que se establecen entre éstos, así como las finalidades que nos proponemos a partir de situarnos en ese mundo.

Por ello, si la finalidad se inscribe en un horizonte de transformación, la educación debe ser entendida como una práctica política, en la medida en que la política no es "el arte del buen gobierno", sino la posibilidad de realizar acciones no reguladas por el Estado, por lo tanto, 
actos de creación. ${ }^{5}$ En este sentido la política hace referencia a acciones y decisiones no reguladas por el poder, orientadas a transformar las relaciones sociales en la que se inscribe y se definen los sujetos y en esta perspectiva, construir realidad y mundo. La política por lo tanto opera en el ámbito de la novedad y de la creación, no en el de la repetición y la regulación. Es el fundamento de la existencia de las personas y de la convivencia humana y, especialmente de la educación.

La educación como práctica política es un proceso basado en una intensa y extensa interacción orientada a la estructuración de los seres humanos como sujetos, con capacidad de comprender y construir los diversos sentidos que sostienen la vida social, pero al mismo tiempo, con capacidad de actuar sobre la realidad, generar nuevas prácticas y relaciones sociales que posibiliten la transformación de sí mismos y del mundo. Meirieu sostiene que la educación es una "relación disimétrica, necesaria y provisional en orden a la emergencia del sujeto". ${ }^{6}$

Pero ¿Qué significa que los seres humanos se estructuren como sujetos? ¿Cuál es el carácter de las relaciones en las cuales los seres humanos devienen sujetos? ¿Por qué los seres humanos tienen que devenir sujetos en el proceso educativo? ¿Para qué los seres humanos nos hacemos sujetos? Éstas son interrogantes que intentaremos dilucidar en el presente artículo, y lógicamente, con el ánimo de construir un acercamiento a esta perspectiva.

Entender la educación como una determinada relación que genera la emergencia del sujeto, es una empresa difícil por la complejidad presente en dicha relación. Las relaciones entre los seres humanos no son simples encuentros, en éstas intervienen la política, ecología, economía y cultura con toda su complejidad, por ello, estas relaciones pueden ser vistas como una red multidi- 
mensional en permanente creación y destrucción en diversos niveles y en diversos tiempos. Edgar Morin plantea dos aspectos que definen esta complejidad: uno dado por el enmarañamiento de acciones, de interacciones, de retroacciones que hacen referencia a aspectos empíricos y otro dado por fenómenos aleatorios imposibles de determinar en esta red multidimensional de relaciones y que hace referencia a aspectos lógicos. La complejidad aparece por lo tanto como una "heterogeneidad organizada" de manera lógica. ${ }^{7}$ El universo y la realidad se caracterizan por esta complejidad y ella misma surge en base a una dialéctica entre orden y desorden que forma el conjunto de organizaciones existentes en el universo. La propia vida aparece en condiciones de esta relación de relaciones y de esta aleatoriedad que hace de ello un proceso tormentoso, contradictorio y conflictivo.

En esta perspectiva, las relaciones en la educación van más allá de la relación entre los hombres en su pura materialidad, es decir una relación entre educando y educador en el aula o escenario educativo como cuerpos biológicos. Esta relación es mas bien una relación de relaciones en un contexto y en un momento histórico determinado, que articula las relaciones que se establecen entre los hombres mediadas por el conocimiento, la relación entre conocimiento y mundo mediada por los hombres y la relación entre hombres y mundo mediada por el conocimiento. En cada uno de estos ámbitos se dan a la vez otras relaciones que configuran el carácter complejo del proceso educativo. No sólo que nosotros nos relacionamos con el conocimiento y con el mundo, también el mundo se relaciona con nosotros, entendiendo al mundo no sólo en su dimensión física, sino también en su dimensión simbólica y cultural. "Todo esta relacionado con todo y viceversa”. El hombre no es más que un plexo 
en esta trama multidimensional de relaciones que constituye la vida. Su propia humanidad le viene dado de su relación con la naturaleza y con otros hombres, es por lo tanto, en el devenir de esta relación que nos volvemos humanos.

Esta relación entre persona, mundo y conocimiento que se da en el proceso educativo, actualmente es una relación de dominación que reproduce el dominio de determinadas clases que controlan la sociedad y el propio conocimiento. Esta relación es autoritaria, fría, represiva, se comunica de manera impersonal, unidireccional y vertical, maneja ciertas verdades que le son funcionales para reproducir estructuras, prácticas, contenidos, modos de pensar, sentir, amar y en definitiva maneras de vivir impuestas por dichas clases, las mismas que son vistas como metas a alcanzar por los dominados, interiorizando un sentimiento de inferioridad y desvalorización de sí mismos.

En esta relación autoritaria de opresión, como dice Freire, el educador se construye como el que sabe, tiene la verdad o por lo menos el secreto para llegar a ella, se convierte en un disertador de conocimientos ya elaborados, en un narrador de hechos consumados, en un medidor de los niveles de repetición de contenidos y metodologías por parte de los educandos, un represor de conductas y comportamientos con el objeto de modelar "mentes obedientes y cuerpos disciplinados" a ser inmolados en el altar del Mercado.

El educando, en cambio, ubicado en el extremo más débil de la relación, se vuelve un ser pasivo y receptivo a la palabra alienada y alienante del educador, un ser en el cual casi se ha extinguido la llama de la creación y la innovación, por lo tanto un ser dependiente, incapaz de salir del mundo de las opiniones, hacer una crítica seria y 
construir nuevos sentidos de su existencia y del mundo. En este escenario la comunicación y el acto cognoscitivo desaparecen del horizonte educativo y la educación se convierte en una transmisión donde el educando es el objeto y el educador el verdadero sujeto de la educación. ${ }^{8}$

Por ello en la reflexión sobre la educación como relación, lo primero que se nos viene a la mente es que esta es una relación comunicativa, siguiendo a Maturana podemos decir que la educación es una "red de conversaciones" en un momento histórico y en un contexto específico. Estas conversaciones son lo central en las relaciones entre los seres humanos y determinan el devenir objeto o sujeto, conversaciones en las cuales el sujeto reconoce al otro en toda su "alteridad" como se reconoce a sí mismo, y desde este reconocimiento se moviliza a su encuentro. Este reconocimiento es aceptación, es decirle sí como persona, es un abrirse al otro, es un darse sin cálculos y estrategias; esta relación es precisamente creación del otro y de uno mismo.

En esta perspectiva la comunicación es un elemento constitutivo de esta relación y de ninguna manera podemos instrumentalizarla. Concebir que hacemos comunicación "para": vender detergente, hacer desarrollo, aprender tal o cual cosa, etc., es un lamentable error en el que hemos incurrido y obedece a la ideología de las élites dominantes. Instrumentalizar la comunicación implica una perversión de las relaciones y de la propia construcción de humanidad. La comunicación es el movimiento del ser hacia el ser como fundamento de su devenir humanidad.

¿Cómo hacer esta comunicación en el proceso educativo? ¿Cómo hacer que la relación educativa sea una relación comunicativa? Quizá la estructura de la escuela en los actuales momentos no es la más adecuada para 
hacer esta comunicación. Una manera de hacer realidad esa relación comunicativa, puede que sea haciendo de la educación una fiesta. ¿Qué significa hacer de la educación una fiesta? ¿Por qué hacer una fiesta?

La fiesta es una institución comunitaria que se construye en base a la cooperación y la solidaridad y en la cual los sujetos se cohesionan y construyen su identidad basados en la participación y al reconocimiento del otro. Es el lugar de la cooperación y la solidaridad, de alegría y de gozo, pero también de la creatividad y la imaginación. La fiesta es por lo tanto un lugar de resistencia al poder, si pensamos como Espinosa que el poder opera en el temor y la tristeza.

Hacer de la educación una fiesta implica desatar la energía creativa, la imaginación, el gozo y, sobre todo, inaugurar una nueva relación donde el otro no es visto como amenaza, sino como un otro diferente, cuya diferencia me enriquece y me recrea y en la cual nos transformamos mutuamente. La educación como fiesta implica trabajar otras dimensiones del ser humano y no sólo el conocimiento como es la educación actual. Además, no todo conocimiento es emancipatorio, éste es tal, si llena las expectativas a las interrogantes realizadas por el sujeto al constituirse como tal y sobre todo si estas respuestas están articulas a proyectos colectivos. ${ }^{9}$

Cuando Don Bosco reivindica el patio como espacio educativo, creo que está apelando precisamente a esta dimensión festiva y amerita una investigación seria para desarrollarla en el contexto actual en el que vivimos. Desgraciadamente en la América Latina colonial y poscolonial, la educación no se dio con esta dimensión festiva. Desconozco si las culturas ancestrales trabajaban de esta manera en el periodo prehispánico y preincaico. Lo que si está claro es que la educación latinoamericana nace 
importada, es externa a los procesos históricos y realidades locales, se inscribe en un proceso de invasión y dominio y por lo tanto nace con un carácter bélico: su valor central es la competencia; su acción fundamental: el disciplinamiento; su práctica la memorización y la repetición de verdades construidas por el poder dominante. Aún hoy, este carácter bélico y de dominio predomina en su esencia, basta ir a cualquier institución educativa y mirar como es la entrada a clases para darnos cuenta de su carácter, peor si hurgamos en su pedagogía, en sus ceremonias, en sus rituales, etc. Su carácter bélico se expresa en una serie de símbolos, como la marcha, formación, uniforme, banda de guerra, etc. Según Siede, en América Latina la educación estuvo instrumentalizada a las estrategias europeas de dominación:

“... la escuela ha sido la continuación de la guerra por otros medios: allí donde las armas dirimieron el destino de los pueblos, la escuela se ocupó luego de consolidar un presente y pasado común. No parece exagerado afirmar que la escuela americana vino a continuación de los ejércitos, para apropiarse de los hijos de los vencidos, para arrebatar su memoria y torcer el rumbo de las generaciones". ${ }^{10}$

De esta manera, es fácil comprender porque en el proceso educativo latinoamericano y ecuatoriano, la comunicación es la gran ausente y la conversación sede al monólogo. Al no existir esta racionalidad comunicativa, al estar instrumentalizada, las relaciones de cooperación y solidaridad son simples deseos; la relación que prevalece finalmente más allá de nuestra voluntad, por la manera como se estructuró y está estructurada nuestra sociedad, es la relación de dominio y competencia.

Estas relaciones que se establecen entre los seres humanos, el conocimiento y el mundo tienen otras impli- 
caciones que son importantes considerarlas para entender el proceso educativo desde la perspectiva del sujeto. Un aspecto importante es el que hace referencia a las afecciones.

Los cuerpos vivientes como cuerpos materiales al entrar en relación con otros cuerpos, de alguna manera entran en su composición, los afectan y al afectarlos, se modifican mutuamente. Los seres humanos al entrar en relación con otros seres humanos nos modificamos y de la misma manera cuando entramos en relación con algún ambiente modificamos ese ambiente, de igual forma que dicho ambiente nos modifica a nosotros. ${ }^{11}$

Baruch Espinosa explica esta mutua afectación en términos de ubicar que todo lo que existe son cuerpos que se encuentran en relación con otros cuerpos y en dicha relación se están afectando los unos a los otros. En este sentido, en el proceso educativo se dan unas determinadas mesclas de cuerpos de educadores y educandos y si la particular manera de mesclarse determina que sea un objeto y no otro, entonces la educación es una manera particular de componerse los cuerpos que determina que sean lo que son. No sólo que nos afectan de una manera directa los cuerpos más próximos, sino indirectamente todos los cuerpos existentes en el universo. ${ }^{12}$

Por ejemplo los procesos gravitacionales de los eventos cósmicos más lejanos influyen en la galaxia y ésta en el sistema solar y éste de alguna manera en el planeta tierra y en el ser humano; algunos cambios que ocurren en las funciones corporales del los animales y del propio ser humano son producto de la influencia de la luna, del sol, de las estrellas, etc., así, el reloj biológico y las funciones fisiológicas de los animales y del propio ser humano están ajustados a los ritmos estacionales. Otro tipo de sucesos que nos afectan son las estructuras sociales, económicas, políticas y culturales. La manera como se estruc- 
tura el trabajo y el consumo, son elementos que me constituyen muy sutil y silenciosamente. Todo lo que entre en el horizonte del ser humano le afecta y es afectado por el ser humano al entrar en determinadas relaciones. Sin embargo, el hecho de que seamos afectados por todo lo que entra en nuestro horizonte, no implica que el ser humano sea un robot biológico que funciona en base a ciertos determinantes ambientales o culturales.

Esta afección aparece como una consecuencia de toda relación y lo que nos interesa es el carácter de esta afección en el proceso educativo y que puede constituirse en un acontecimiento en la vida del sujeto, pues esta afección al generar cambios en la comprensión del mundo y del propio ser humano, genera cambios en las relaciones y en las acciones del ser humano.

Por otra parte, las relaciones que constituyen lo humano no son solamente biológicas, son también culturales y se construyen en medio de una profunda emocionalidad. Bonano plantea que la psiquis tiene una estructura grupal que aparece como una constitución hacia el interior de los grupos en los cuales él se ha conformado como sujeto y que es animada por la realización de los deseos que surgen de lo pulsional. Todo este proceso es lo que el psicoanálisis llama la fuerza fantasmática, que no es más que la figuración de los deseos del sujeto bajo la forma de una escena que se estructura con las formas y contenidos culturales aportados por los mitos, los relatos, es decir con las significaciones sociales ${ }^{13}$. Por lo tanto, el psiquismo emerge apoyado en el cuerpo biológico, pero en relación con otros psiquismos, sobre todo el de la madre que se encuentra sumergido en el océano simbólico, con el cual aprende la cultura. A pesar de la importancia que tiene el psiquismo en su totalidad para entender los procesos de constitución del sujeto, son las emociones y los afectos lo que nos interesa. 
Podríamos hacer una rigurosa diferenciación entre pulsión, afecto y emoción, pero para los propósitos de este trabajo y dado su alcance utilizaremos los términos emoción y afecto indistintamente. Según Chodorow, las emociones son sinónimos de afectos que contribuyen a moldear el psiquismo y construir las imágenes internas. ${ }^{14}$ Existe un amplio debate sobre la génesis y estructura de las emociones o afectos. Desde la perspectiva cultural se plantea que la experiencia está determinada por la cultura de cada uno, pues los seres humanos no respondemos a objetos externos como tales, sino a la significación que esos objetos tienen para nosotros. Desde esta perspectiva, el lenguaje crea la significación que construye la experiencia, por ello, la emoción como una de las tantas cosas que se experimenta, es creada culturalmente y no tiene relación con la biología, debido a que el símbolo no tiene relación con las cosas empíricas. ${ }^{15}$ De esta manera, la antropología simbólica plantea que las emociones son construcciones culturales que existen únicamente en el universo de las categorías culturales. ${ }^{16}$

Desde la psicología, se plantea en cambio que las emociones incorporan la significación cultural, pero no están totalmente moldeadas por ellas. Las emociones son creaciones de las personas. Desde la perspectiva que estamos reflexionando, éstas surgen en la dialéctica de la relación organismo y medio y; por lo tanto, nos inclinamos a pensar que si bien son determinadas por la cultura, éstas tienen una base biológica. Desde la biología se piensa que en el ser humano las emociones se realizan en el cerebro; el ser humano necesita del sistema neural para aprender a partir de la experiencia, para construir planes de comportamiento y para sobrevivir, es decir necesita de los afectos y de las emociones. Maturana explica este proceso, en términos de que los seres humanos somos antes que seres racionales, "animales emocionales". ${ }^{17}$ 
No existe acción humana sin una emoción que la fundamente. Las emociones o afectos constituyen un aspecto central en la vida del ser humano, participan en todo lo que hacemos y vienen a ser como la pantalla sobre la cual se construyen nuestras acciones. Si no existe la emoción, no existe la acción, la emoción precede a la acción, es la energía fantasmática que generan los sujetos en su interacción. La emoción para Maturana es el "dominio de acciones en el que un animal se mueve"18, es el proceso de interacción social entre dos o más sujetos para organizar la supervivencia. Esta vida afectiva y emocional se puede observar de manera intensa en la relación entre madre e hijo pequeño, donde las emociones son "diferentes maneras de interactuar". 19

Podemos entender las emociones como un conjunto de prácticas universales de la cultura en interacción con una herencia biológica común y procesos de interacción social. Por lo tanto, las emociones antes que referirse a estados internos, designan fuerzas que sostienen procesos comunicativos y culturales. ${ }^{20}$

¿Qué es lo que nos mueve a que tengamos interés en el otro? Maturana dice: es el amor como emoción que constituye la coexistencia social. Necesitamos explicaciones racionales cuando nuestro interés se orienta a otros seres humanos que no son miembros de nuestra misma comunidad. Este modo de vivir de lo humano en intimidad, se estableció cuando se comenzó a vivir en el lenguaje, por ello, nosotros vivimos en comunidades que no son más que redes de comunicación. La razón opera a través de emociones que surgen en nosotros en el transcurso de nuestras conversaciones. Una conversación no es más que un flujo de coordinación de acciones y emociones presentes y futuras, actuales y posibles, que se expresan como quejas y disculpas, deseos y expectativas, mandos y obe- 
diencias, caracterizaciones y atribuciones. ${ }^{21}$ Esta aceptación mutua, este reconocimiento del otro, este movimiento que realiza el sujeto hacia el otro, este vivir en la cooperación y la colaboración es lo que Maturana llama la "emoción del amor".

Para Kristeva el amor es un planteamiento fundamental en el psicoanálisis, puesto que Freud hizo del amor una terapia con el objeto de reestablecer la realidad. Kristeva entiende obviamente el amor, como apertura hacia el otro, puesto que el psiquismo es un sistema abierto y conectado con el otro. En este sentido, Kristeva dice que “...si nuestro psiquismo no está emocionado, está muerto".22 El psicoanálisis asocia el estado amoroso al narcisismo. La elección de un objeto de amor resulta satisfactoria, siempre y cuando hay un otro idealizable que se remita a mi propia imagen. El amor es una clase de emoción o afecto que se expresa en un movimiento hacia el otro, esencial para el vínculo y la interacción, pero sólo posible si yo me veo reflejado en el otro. ${ }^{23}$

Hasta ahora hemos planteado que el sujeto es un organismo viviente que se construye en su relación con el mundo y con los otros organismos vivientes. Que en esta relación afecta y es afectado y para que esta se constituya tiene que estar abierto al otro, lo cual implica entrar en comunicación. Como organismo viviente, está determinado por las leyes de la biología y como tal está enfrentado a la muerte e inserto en el circuito natural de la vida que lo condiciona y lo precede. El ser humano tiene la urgencia de vivir en este circuito natural de la vida, tiene una necesidad material de existencia. Por lo tanto, el sujeto no aparece como sujeto con necesidades sino como sujeto necesitado que se plantea fines para satisfacer sus necesidades pero dentro de una racionalidad de reproducir la vida. ${ }^{24}$ 
Hinkelamert nos exhorta a abandonar la racionalidad instrumental y entrar en la lógica de la racionalidad reproductiva de la vida que implica estructurar una manera de vivir, sobre la base de los siguientes principios.

- Enfrentar la muerte para evitar el derrumbe de todos los fines.

- La afirmación de la vida no es un fin en sí mismo, es un proyecto orientado a convertirnos en sujetos para tener fines.

- Desplegar acciones para evitar amenazas a la vida mediante un aprendizaje permanente.

- Sus valores son el respeto, la colaboración y la solidaridad.

- Debido al carácter social, el sujeto tiene que defender la vida del otro para defender su propia vida.

- La constitución de la realidad objetiva por el reconocimiento entre sujetos, es decir el reconocimiento del otro en una relación mutua como seres naturales necesitados. ${ }^{25}$

La contradicción que emerge de la oposición entre una manera de vivir impuesta por el capital y que configura el mundo, la misma que es reproducida por la educación y la necesidad de construir una manera de vivir solidaria, nos permite pensar en el sujeto como contradictor. Éste sólo puede aparecer en la trasgresión de lo dado, de lo constituido, puesto que éste es un orden que destruye la vida y al propio ser humano, lo somete a la ley del valor establecido por el mercado y la racionalidad instrumental. El sujeto necesitado, por lo tanto se ve en el imperativo de revelarse contra ese orden y contra la ley, si esta no le deja lugar para vivir. ${ }^{26}$ Hacer educación para 
sostener la vida del otro y la mía propia, promover la liberación del ser humano de todas las estructuras simbólicas y culturales que lo dominan y destruyen, construir nuevas relaciones e instituciones que promuevan esas relaciones, es trabar por la emergencia del sujeto.

Este enfrentamiento con el orden aparece como hecho constitutivo del sujeto y nos lleva a entenderlo como la búsqueda de los individuos en comunidad a sostener su existencia con dignidad y a crear las condiciones que le permitan ser los actores de su propia historia. Lo que motiva esta búsqueda, es el sufrimiento de los seres humanos provocado por el sometimiento a este mundo totalizado del mercado que los destruye y los lleva a reivindicar su derecho a la existencia como sujetos vivientes en comunidad. ${ }^{27}$

Por ello, el sujeto es un actor social capaz de modificar su contexto desde un fundamento ético radical. Es una fuerza que resiste al poder en nombre de la libertad y la equidad. Es una fuerza ética frente a las redes de información y los sistemas económicos y políticos globalizados. ${ }^{28}$ El no sujeto es el sinsentido en nosotros. En el caso del mercado, el Estado, los medios o en cualquier otra circunstancia, el sentido está fuera de nosotros, está en el poder.

El sujeto tiene algunas características adicionales, entre las cuales podemos citar las siguientes: Singularidad, emotividad, reflexividad epistemológica, ética y estética $y$, finalmente, creatividad entre las más importantes.

Con respecto a la singularidad es necesario tener en cuenta que el sujeto tiene una corporeidad por el hecho de ser un organismo vivo, corporeidad que es también construida socialmente, constituyendo lo que llamamos corporalidad. Como corporalidad y corporeidad el 
sujeto es único e irrepetible; es decir, es una singularidad y puede darse sólo en sociedades que tienen como principio la diversidad. En sociedades totalitarias donde el poder trata de controlar el cuerpo de los otros, el sujeto como singularidad emerge como contradictor de ese poder, por ello, la educación tiene que afirmarse en la diversidad y al mismo tiempo desarrollar políticas, procedimientos, metodologías y didácticas para que emerjan esas particularidades autónomas de cualquier doctrina o ideología.

La diversidad parece que es el principio de la vida y de la realidad. Todo cuerpo se expresa por el hecho de ocupar un lugar en el espacio - tiempo, es más, "devienen a la existencia como cuerpos singulares y particulares" y constituyen un universo que constantemente se está componiendo y recomponiendo. ${ }^{29}$ Estos cuerpos devienen a la existencia y al hacerlo, inauguran una determinada temporalidad, una específica manera de pasar el tiempo. Esta manera única de pasar el tiempo, de ocupar de una manera determinada el espacio y de ser afectado por otros cuerpos hace que estos cuerpos sean únicos, constituyan la diversidad de la realidad y posibiliten la emergencia constante de lo nuevo como heterogéneo. ${ }^{30}$

Estas particularidades no se quedan únicamente en la proliferación de nuevas realidades individuales, en la emergencia de lo nuevo, sino que, esta emergencia forma también multiplicidades en un conflicto, en un campo de lucha con las particularidades. Estas multiplicidades son maneras de vivir el tiempo y ocupar el espacio que se han totalizado en el conflicto y que se expresan como formas socio - culturales. ${ }^{31}$

Esta construcción que fundamenta la emergencia de lo nuevo, nos permite comprender como el horizonte cultural, determinado por el poder de una clase, 
obstaculiza la emergencia de la novedad o permite que éste se de en el límite dé ese horizonte. Sin embargo, no todos los sucesos están determinados y por ende el horizonte de sucesos está también indeterminado, lo cual implica que no sólo es posible realizar sucesos no determinados, sino que también se puede construir y crear otro horizonte. Esta creación de otro horizonte y la estructuración de una relación para que emerja el sujeto, es la tarea del sujeto y por ende de la educación.

Otra característica del sujeto es su capacidad de creación la que se realiza a través de la imaginación entendida como la capacidad de invención de representaciones y sentidos en la vida cotidiana de una sociedad". ${ }^{2}$ Siguiendo a Castoiriadis, Bonano toma lo imaginario como un material asociado con la reproducción y producción de la sociedad, algo que permite la creatividad política y no como lo ilusorio y falso en la perspectiva del positivismo. La indeterminación del ser en el plano de lo social implica necesariamente la posibilidad de lo nuevo, una nueva manera de ser social, cuyo proceso operativo se inicia imaginándolo, para luego concretarlo y hacerlo efectivo aquello que existía tan sólo como posibilidad.

Desde esta perspectiva hay un imaginario "efectivo" que está asociado con la tarea de reproducción de la sociedad y los procesos de determinación y, por otro lado, un imaginario "radical" asociado con la capacidad de los sujetos de "instituir-inventar-crear" significaciones, formas e instituciones sociales que corresponden a los procesos de indeterminación. ${ }^{33}$. El imaginario radical es la capacidad de la psique de "crear" un flujo constante de representaciones, deseos y afectos, pero en términos de lo social, hace referencia a la creación de lo social.

Esta producción de imaginarios se realiza a través de la reflexión y constituye una tercera característica 
del sujeto. Una característica de los cuerpos vivos es su capacidad de reflexión, es decir la capacidad de volver sobre sí mismos de manera refleja, para alterarse. Rojas recurre a la reflexión estética como modelizante del conjunto de relaciones sociales, característica propia de los cuerpos particulares que reflejan su intensidad y sus afectos. El cuerpo reflejado es un cuerpo nuevo que aparece como "mímesis de pasar el tiempo" y, por lo tanto, la reflexividad estética aparece como una capacidad del sujeto de construirse sobre sí mismo. ${ }^{34}$ Rojas dice que “... los sujetos sociales se constituyen como cuerpos expresivos y reflexivos, que vuelven constantemente sobre sí mismos, de modo reflejo, y que en este mirarse y alterarse, adquieren alguna forma de conciencia de sus propios procesos". 35

De esta manera el sujeto tiene la capacidad de expresarse reflexivamente, de ser una novedad en el universo, de crear otra forma de ser sociedad, pero para hacerlo necesita conocer la cultura. La educación es vital y entra en ese conflicto entre lo constituyente y lo constituido, entre lo nuevo y lo viejo. Crear nueva sociedad es una tarea que emerge de lo existente, pero conocer lo existente tiene que ser una actividad profundamente crítica, sólo de esa manera puede también la educación ubicarse en la novedad y la creación y, sobre, todo en la emergencia del sujeto.

En esta perspectiva, cada época histórica es el modo de imponer el tiempo de uno sobre el tiempo de los otros. Los sujetos sociales se caracterizan por elegir el camino para transitar desde una determinación hacia un nuevo modo de pasar el tiempo, aunque lo hagan siempre al interior de un horizonte de sucesos determinado por la época histórica en la que viven. Una época histórica impone un horizonte de sucesos, un modo de pasar el 
tiempo sobre los demás tiempos, en este sentido el tiempo de la modernidad y del capital establece la forma en que se pasa el tiempo, mediante la búsqueda de rentabilidad y la búsqueda de dominio de unos sujetos sobre otros.

Devenir sujeto social es seguir una trayectoria en ese espacio-tiempo y hacer que emerja una temporalidad determinada a partir de las indeterminaciones que caracteriza a toda realidad en medio de las asimetrías y distorsiones que genera el propio tiempo del capital. Aquí se genera una nueva subjetividad que supone una nueva temporalidad dada por la capacidad de los sujetos de romper el horizonte de sentido del capital y establecer otras formas de existencia.

De esta manera, la educación en la medida que actúa en estas relaciones entre los seres humanos, que genera afecciones de manera deliberada, y que busca que emerjan estos seres humanos con ciertas características, no puede dar cuenta solamente del proceso técnico del aprendizaje y de la enseñanza, sino de cómo nos constituimos como seres humanos, más específicamente siguiendo a Meirieu y Freire, de cómo nos constituimos como sujetos. Este es el reto que enfrenta la educación actualmente y estoy seguro es el camino para llegar a estados de conciencia social, de democracia, de justicia, de equidad y libertad, nunca antes soñados. 


\section{Notas}

1 http://www.educacion.gov.ec/noticias/noticias.php?nav=noticias\&varCodBol=1192\&offset=7 Informe del Ministro de Educación Raúl Vallejo sobre los resultados de las pruebas tomadas a los aspirantes a docentes. 29/02/2008.

2 Freire, Paulo. Pedagogía de la indignación, Madrid, Ediciones Morata, 2001, p. 41.

3 La educación por competencias que hoy está de moda, no es más que la funcionalización de los procesos educativos a las lógicas del mercado, con el afán de capacitar mano de obra diestra en realizar determinados procesos para incrementar la productividad.

4 Fritjof Capra. La trama de la vida, Barcelona, Editorial Anagrama, 2000, p. 184.

5 Badiou, Alain. ¿Qué es la política? Conferencia en el Encuentro Permanente por un Nuevo Pensamiento, realizada del 24 al 25 de abril del 2000 en Argentina. Documento fotocopiado. pp. 10-12.

6 Meirieu, Philippe. La opción de educar. Ética y pedagogía. Barcelona, Octaedro, 2001, p. 30.

7 Morin, Edgar. Epistemología de la complejidad en "Nuevos Paradigmas, cultura y subjetividad”. Buenos Aires, Editorial Piados, 1995. p. 422.

8 Freire, Paulo. Pedagogía del oprimido, México, XXI, 54º Edición, 2002, p. 74.

9 Siede, Isabelino. La educación política, Buenos Aires, Editorial Paidós, 2007, pp. 55-57.

10 Ibíd. p. 59.

11 Deleuze, Giles. Espinosa y el Poder, Curso sobre Spinoza del 24 de enero de 1978. Documento fotocopiado. pp. $5-8$.

12 Osvaldo Bonano. La dimensión del apuntalamiento en Crisis del sujeto contemporáneo, Facultad de Ciencias Sociales Universidad de Lomas de Zamora, Argentina, 2000, pp. 174 - 176.

13 Chodorow, Nancy. El poder de los sentimientos, Buenos Aires, Editorial Paidós, 2003, p. 13.

14 Ibíd. pp. $174-175$.

15 Ibíd. p. 214.

16 Maturana, Humberto. La objetividad: un argumento para obligar, Bogotá, Editorial Dolmen, 1998, p. 110.

17 Ibíd. p. 21.

18 Ibíd. p. 56. 
19 Chodorow, Nancy. El poder de los sentimientos, Buenos Aires, Editorial Paidós, 2003, p. 191.

20 Maturana, Humberto. La objetividad: un argumento para obligar, Bogotá, Editorial Dolmen, 1998, pp. 66.

21 Kristeva, Julia. Historias de amor, México, Editorial Siglo XXI, 2000, p. 12.

22 Ibíd. p. 338.

23 Ibíd. p. 21.

24 Hinkelamert Franz. El retorno del sujeto reprimido, Universidad Nacional de Colombia, Bogotá, 2002, p. 244.

25 Hinkelammert, Franz. El grito del sujeto, DEI, Costa Rica, 1998, p. 36.

26 Touraine Alain. ¿Podemos vivir juntos?, Fondo de cultura económica, Buenos Aires, 1997, p. 65.

27 Touraine Alain. A la búsqueda de si mismo, Barcelona, Editorial Paidós, 2002, p. 111.

28 Ibíd. p. 23.

29 Rojas, Carlos. Cuerpos, expresión y política, Universidad de Cuenca, Cuenca, 2000, p. 24.

30 Ibíd. p. 26.

31 Osvaldo Bonano. Lo imaginario social: el enfoque ontológico de Cornelius Castoriadis en Crisis del sujeto contemporáneo, Facultad de Ciencias Sociales Universidad de Lomas de Zamora, Argentina, 2000, p. 70.

32 Íbíd. pp. $70-78$.

33 Ibíd. p. 34

34 Rojas, Carlos. Cuerpos, expresión y política. Universidad de Cuenca, 2000. p. 22. 


\section{BIBLIOGRAFÍA}

CHODOROW, Nancy

2003 El poder de los sentimientos. Buenos Aires, Editorial Paidós,. DELEUZE, Giles

Curso sobre Spinoza el 24 de enero de 1978. Documento fotocopiado.

FREIRE, Paulo

2002 Pedagogía del oprimido. México, XXI.

962001 Pedagogía de la indignación. Madrid, Ediciones Morata.

HINKELAMERT, Franz

El retorno del sujeto reprimido. Bogotá. Universidad Nacional de Colombia, Bogotá.

HINKELAMMERT, Franz

El grito del sujeto. Cota Rica, DEI.

KRISTEVA, Julia

2000 Historias de amor. México, Editorial Siglo XXI.

MATURANA, Humberto

1998 La objetividad: un argumento para obligar. Bogotá, Editorial Dolmen.

MEIRIEU, Philippe

2001 La opción de educar. Ética y pedagogía. Barcelona, Octaedro.

MORIN, Edgar

1995 Nuevos Paradigmas, cultura y subjetividad. Buenos Aires, Editorial Piados.

BONANO, Osvaldo

2000 Crisis del sujeto contemporáneo. Facultad de Ciencias Sociales Universidad de Lomas de Zamora, Argentina.

ROJAS, Carlos

2000 Cuerpos, expresión y política. Universidad de Cuenca.

SIEDE, Isabelino

2007 La educación política. Buenos Aires, Editorial Paidós.

TOURAINE Alain

1997 ¿Podemos vivir juntos? Buenos Aires, Fondo de cultura económica.

TOURAINE Alain

2002 A la búsqueda de sí mismo. Barcelona, Editorial Paidós. 